\title{
Subunit Dissociation and Diffusion Determine the Subcellular Localization of Rod and Cone Transducins
}

\author{
Derek H. Rosenzweig, ${ }^{1 \star}$ K. Saidas Nair, ${ }^{1 \star}$ Junhua Wei, ${ }^{2}$ Qiang Wang, ${ }^{1}$ Greg Garwin, ${ }^{3}$ John C. Saari, ${ }^{3}$ Ching-Kang Chen, ${ }^{4}$ \\ Alan V. Smrcka, ${ }^{5}$ Anand Swaroop, ${ }^{6}$ Janis Lem, ${ }^{7}$ James B. Hurley, ${ }^{2}$ and Vladlen Z. Slepak ${ }^{1}$ \\ ${ }^{1}$ Department of Molecular and Cellular Pharmacology and Neuroscience Program, University of Miami Miller School of Medicine, Miami, Florida 33136, \\ Departments of ${ }^{2}$ Biochemistry and ${ }^{3}$ Ophthalmology, University of Washington, Seattle, Washington 98195, ${ }^{4}$ Department of Biochemistry, Virginia \\ Commonwealth University, Richmond, Virginia 23284, 5 Department of Pharmacology and Physiology, University of Rochester School of Medicine and \\ Dentistry, Rochester, New York 14603, 'Departments of Ophthalmology and Visual Sciences, and Human Genetics, University of Michigan, Ann Arbor, \\ Michigan 48109, and ${ }^{7}$ Molecular Cardiology Research Institute, Tufts-New England Medical Center, Boston, Massachusetts 02111
}

Activation of rod photoreceptors by light induces a massive redistribution of the heterotrimeric G-protein transducin. In darkness, transducin is sequestered within the membrane-enriched outer segments of the rod cell. In light, it disperses throughout the entire neuron. We show here that redistribution of rod transducin by light requires activation, but it does not require ATP. This observation rules out participation of molecular motors in the redistribution process. In contrast to the light-stimulated redistribution of rod transducin in rods, cone transducin in cones does not redistribute during activation. Remarkably, when cone transducin is expressed in rods, it does undergo light-stimulated redistribution. We show here that the difference in subcellular localization of activated rod and cone G-proteins correlates with their affinity for membranes. Activated rod transducin releases from membranes, whereas activated cone transducin remains bound to membranes. A synthetic peptide that dissociates G-protein complexes independently of activation facilitates dispersion of both rod and cone transducins within the cells. This peptide also facilitates detachment of both G-proteins from the membranes. Together, these results show that it is the dissociation state of transducin that determines its localization in photoreceptors. When rod transducin is stimulated, its subunits dissociate, leave outer segment membranes, and equilibrate throughout the cell. Cone transducin subunits do not dissociate during activation and remain sequestered within the outer segment. These findings indicate that the subunits of some heterotrimeric G-proteins remain associated during activation in their native environments.

Key words: retina; rod; cone; transducin; signal transduction; diffusion

\section{Introduction}

The physiological state of a neuron is influenced by the distribution of signaling proteins within it. Some processes, e.g., axonal transport and mitochondrial import, use energy from ATP hydrolysis to distribute proteins, but simple diffusion and proteinprotein or protein-lipid interactions also can determine distribution. For instance, scaffolding proteins influence the distributions of cAMP signaling enzymes (McConnachie et al., 2006), and protein-membrane interactions determine the subcellular distribution of Ras (Feig, 2006).

Photoreceptors are highly polarized neurons. On one end of

Received Feb. 7, 2007; accepted April 16, 2007.

This work was supported by National Institutes of Health Grants GM 060019 (V.Z.S.), EY 06641 (J.B.H.), EY12008 (J.L.), EY13811 (C.-K.C.), EY11115 (A.S.), and GM60286 (A.V.S.), American Heart Association Florida Affiliate Fellowships (K.S.N., D.H.R.), and a grant from the Hope-for-Vision Foundation (V.Z.S.). We are grateful to Alison Scott and Zhogyan Wang for technical assistance. We also thank Valery Shestopalov (Bascom Palmer Eye Institute, Miami, FL) for invaluable help with confocal microscopy.

${ }^{*}$ D.H.R. and K.S.N. contributed equally to this work

Correspondence should be addressed to either of the following: Vladlen Z. Slepak, Department of Molecular and Cellular Pharmacology and Neuroscience Program, University of Miami Miller School of Medicine, Miami, FL 33136, E-mail: v.slepak@miami.edu; or James B. Hurley, Department of Biochemistry, University of Washington, Seattle, WA 98195, E-mail: jbhhh@u.washington.edu.

DOI:10.1523/JNEUROSCI.1421-07.2007

Copyright $\odot 2007$ Society for Neuroscience $\quad$ 0270-6474/07/275484-11\$15.00/0 the cell is a membrane-enriched dendritic structure known as the outer segment (OS). There, activation of rhodopsin by light facilitates binding of GTP to the G $\alpha$ subunit of transducin, a heterotrimeric G-protein. On the opposite end of the photoreceptor is an axon leading to a glutaminergic synapse. Photoactivation of the G-protein cascade in the OS leads to rapid hyperpolarization of the entire neuron, which suppresses glutamate release.

A striking example of signal-induced protein redistribution occurs in rod photoreceptor cells. In darkness, transducin is sequestered within the OS. In light, it disperses throughout the entire cell, reaching the synapse, in $<30 \mathrm{~min}$ after the onset of illumination. Two other photoreceptor proteins, arrestin and a $\mathrm{Ca}^{2+}$-binding protein, recoverin, also distribute differently in light and darkness (Sokolov et al., 2002; Mendez et al., 2003; Elias et al., 2004; Strissel et al., 2005). The redistribution of proteins within rods correlates with a 10 -fold decrease in the gain of phototransduction (Sokolov et al., 2002; Kassai et al., 2005).

Arguments favoring either active transport or diffusion as the mechanism for protein migration in photoreceptors have been discussed (Marszalek et al., 2000; Lee et al., 2003; Lee and Montell, 2004; Nair et al., 2005a; Strissel et al., 2006). In a previous report, we showed that movement of arrestin does not require molecular motors; it occurs even without ATP (Nair et al., 2005). 
Here we show that redistribution of transducin also requires no ATP.

The widely held view that heterotrimeric G-protein complexes dissociate during activation (Gilman, 1987) primarily derives from early studies of rod transducin, whose subunits dissociate and detach from membranes during activation (Kuhn, 1980; Fung et al., 1981). In a recent review, Calvert et al. (2006) hypothesized a link between transducin subunit dissociation, diffusion, and redistribution. Here we provide direct experimental evidence that dissociation and diffusion of subunits are all that is required for redistribution of transducin in rods.

In cones, transducin remains in the OS even under intense illumination (Elias et al., 2004; Kennedy et al., 2004; Coleman and Semple-Rowland, 2005). Rods and cones express different visual pigments and transducins. It has been suggested that a shorter lifetime of light-activated cone visual pigment or activated cone transducin may explain the different distributions of transducin in cones versus rods (Lobanova et al., 2007). We show here that factors influencing the rate of transducin activation and inactivation are not crucial. Instead, transducin in cones does not redistribute in light simply because its subunits do not dissociate even during complete activation.

\section{Materials and Methods}

Animals and tissue preparation. Animal research was conducted in compliance with the National Institutes of Health Guide for the Care and Use of Laboratory Animals and was approved by the Institutional Animal Care and Use Committee. After the required period of dark or light adaptation, mice were anesthetized with isoflurane and killed by cervical dislocation, and the eyes were enucleated. The eyecups or retinas were prepared by removing the cornea and lens in a dark room under a dissection microscope as described previously (Nair et al., 2005a) and maintained in culture in DMEM supplemented with or depleted of certain ingredients as required by a particular experiment.

Immunofluorescence. The tissues were fixed with $4 \%$ paraformaldehyde, embedded in agar, sliced, and immunostained as described previously (Nair et al., 2005a). Antibodies against rod and cone $\mathrm{G} \alpha$ subunits were from Santa Cruz Biotechnology (Santa Cruz, CA). The secondary antibody was cyanine 3-conjugated affinity-purified donkey anti-rabbit IgG (Jackson ImmunoResearch, West Grove, PA). The preparations were then mounted on a coverslip using Antifade reagent (Invitrogen, Carlsbad, CA) and visualized first in the open field with a Nikon (Tokyo, Japan) TE3000 fluorescence microscope, and then the images were taken on a Zeiss (Oberkochen, Germany) LSM 510 laser scanning confocal microscope. Quantification of the relative amount of transducin in the OS and the inner compartments was determined using MetaMorph software (Universal Imaging, Downingtown, PA). Briefly, an area of the visual field was selected (see Fig. $2 C$ ) to include the entire photoreceptors length, from the OS to synaptic termini. The total fluorescence, $F_{\mathrm{t}}$, was measured. Within the same selected area, we recorded the fluorescent signal from the regions corresponding only to the OS or the inner compartments [inner segment (IS), outer nuclear layer (ONL), outer plexiform layer (OPL)], which we designated $F_{\mathrm{o}}$ and $F_{\mathrm{i}}$, respectively. To normalize to data between independent experiments, we determined the $F_{\mathrm{i}} / F_{\mathrm{t}}$ or $F_{\mathrm{o}} / F_{\mathrm{t}}$ ratio. For every image, three separate areas were selected, and the mean and SD were determined. The exposure time and other parameters were set so that none of the areas within the field was saturated. For rod photoreceptors, analysis of a single confocal plane or the collapsed series of confocal images produced essentially the same results. For image presentation purposes only, so that the relatively dim fluorescence in the inner compartments could be clearly visible in the print, the OS areas had to be saturated. It should be noted here also that, although it may appear that the immunofluorescence intensity in the inner compartments is low compared with the OS, the combined area of IS, ONL, and OPL is larger than that of OS, and so the total amount of the antigen in the inner compartments is higher than it may appear from the visual assessment of image intensity.
Ex vivo experiments. Eyecups or retinas were dissected under the dim red light and incubated in DMEM as described previously (Nair et al., 2005a). ATP depletion was performed by incubating the specimen for 15 min in DMEM free of glucose and sodium pyruvate and supplemented with $2 \mathrm{~mm}$ deoxyglucose and $5 \mathrm{~mm} \mathrm{KCN,} \mathrm{pH} \mathrm{7.5.} \mathrm{For} \mathrm{permeabilization,}$ retinas were incubated with $50 \mu \mathrm{g} / \mathrm{ml} \alpha$-toxin (Hemolysin; Sigma, St. Louis, $\mathrm{MO}$ ) for $45 \mathrm{~min}$ at room temperature. The nucleotides were added at the concentration of $0.1 \mathrm{~mm}$. GDP, GTP, GDP $\beta$, and GTP $\gamma \mathrm{S}$ were from Sigma, and BODIPY (4,4-difluoro-4-bora-3a,4a-diaza-s-indacene fluorophore)-GTP $\gamma \mathrm{S}$ was from Invitrogen. The sample incubated with BODIPY-GTP $\gamma S$ was washed for at least $1 \mathrm{~min}$ in the medium or isotonic buffer to remove excess fluorescence before fixing.

Biochemical assays. SDS-PAGE, Western blot, and preparation of bovine and mouse OS were performed as described previously (Nair et al., 2004). For transducin membrane association assay, the OS were resuspended in $100 \mu$ l of buffer $(20 \mathrm{~mm}$ Tris- $\mathrm{HCl}$, pH 7.5, $100 \mathrm{~mm} \mathrm{KCl}$, and 1 mM DTT) with or without the nucleotide as required by a specific experiment, incubated in light or dark for $15 \mathrm{~min}$, and centrifuged. The pellet was resuspended to the same volume as the supernatant, and both samples were analyzed by Western blot.

For trypsin protection assay, the OS membranes were incubated with GTP $\gamma \mathrm{S}$, and then trypsin was added at a concentration $(100-500 \mathrm{ng})$, as required by the experiment. After $15 \mathrm{~min}$ incubation at $20^{\circ} \mathrm{C}$, the reactions were stopped by addition of SDS-containing sample buffer for SDS-PAGE and Western blot analysis.

To study subunit dissociation by size-exclusion chromatography, bovine OS membranes were incubated in light in the presence or absence of GTP $\gamma \mathrm{S}$, and then sodium cholate was added to the final concentration of $1 \%$. The slurry was centrifuged at $40,000 \mathrm{rpm}$ for $30 \mathrm{~min}$, and the extract was resolved on a $1 \times 25 \mathrm{~cm}$ Superdex 75 column. The column was equilibrated with the buffer containing $1 \%$ cholate, and the collected fractions were analyzed by Western blot to detect rod or cone $\mathrm{G} \alpha_{\mathrm{t}}$ subunits. In the experiments with mSIRK (myristoylated G $\beta \gamma$-binding peptide) (see Fig. $8 B$ ) and to fractionate the extracts from dissected mouse retinas (see Fig. 5B), 4-mm-diameter columns were used to reduce the volume. The volume of collected fractions was $0.3 \mathrm{ml}$ for the $1 \mathrm{~cm}$ column and $60 \mu \mathrm{l}$ for the $4 \mathrm{~mm}$ columns. Blue dextran, hemoglobin, and cytochrome $c$ (Sigma) were used as internal molecular weight standards.

Retinoid analyses. Eyecups prepared in culture medium in darkness were exposed to $5 \mathrm{~min}$ of additional darkness, $5 \mathrm{~min}$ of direct sunlight, or 5 min of illumination from a hand-held UV illuminator placed $0.5 \mathrm{~cm}$ directly above the eyecup in a culture dish. The power output of the UV illuminator is described in the text. After 5 min of dark or illumination, eyecups were immediately frozen on dry ice. All subsequent steps were performed in dim red light. The frozen eyecups (four per sample) were thawed, homogenized, extracted, and analyzed by normal-phase HPLC as described previously (Garwin and Saari, 2000). An internal standard, Etretinate (all-trans-9-(4-methoxy-2,3,6-trimethylphenyl)-3,7,-dimethyl2,4,6,8-nonatetraen-1-ethyl ester), was used as described previously (Saari et al., 2002).

Analysis of $\mathrm{N}$-myristoylation. Samples for mass spectrometry analysis were prepared using the method developed by the Crabb laboratory (http://www.lerner.ccf.org/eye/crabb/protocols/). The membrane and soluble fractions obtained from bovine or mouse OS were resolved by SDS-PAGE and stained by Coomassie blue. The bands corresponding to rod or cone $\mathrm{G} \alpha$ subunits were excised, washed with ethanol/water solutions, and dried using a Speedvac. The dried gel slices were rehydrated overnight in a Tris-HCl, $\mathrm{pH} 7.4$, buffer containing $0.01 \mathrm{mg} / \mathrm{ml}$ trypsin. The hydrolizate was extracted in a 60:40 acetonytryl solution, separated from the residual gel, lyophilized, and stored at $-20^{\circ} \mathrm{C}$. They were then dissolved in water (HPLC purity) with $5-10 \%$ of acetonitrile (HPLC purity) and subjected to reverse-phase liquid chromatography followed by mass spectrometry as described previously (Kennedy et al., 2001; Lee et al., 2002). The synthetic N-myristoylated (C14:0) peptides and $\mathrm{N}$-terminal tryptic peptides (GAGASAEEK and GSGISAEDK for rod and cone $\mathrm{G} \alpha_{\mathrm{t}}$, respectively) were purchased from Alpha Diagnostic (Austin, TX) and were used as standards to optimize the HPLC gradient, mass spectrometer settings, and collisionally induced dissociation (CID) tandem mass spectrometry conditions. Selected ion monitoring strongly 
improves the detection sensitivity of small amount of peptides in a digestion mixture. Data from the mass spectrometer were filtered through narrow mass windows ( $1 \mathrm{Da}$ ) centered on the predicted masses of the various fatty acylated $\mathrm{N}$-terminal peptides of the rod and cone transducin being analyzed. To obtain relative amounts of the various fatty acyl species in a given sample, we integrated the area under peaks confirmed by CID to be transducin $\mathrm{N}$ termini. The relative amount of each species was calculated as a fraction of the total amount of rod or cone transducin peptide in membrane-bound or GTP $\gamma \mathrm{S}$ solubilized fraction.

\section{Results}

Transducin redistribution does not require ATP, but it is controlled by guanine nucleotides

In a previous study, we deprived mouse retinas of energy to show that ATP is not needed for redistribution of arrestin. We depleted ATP from freshly dissected mouse retinas by incubating them in glucose-free medium in the presence of deoxyglucose and $\mathrm{KCN}$. ATP depletion did not interfere with redistribution of arrestin, but it blocked light-induced redistribution of rod transducin (Nair et al., 2005a). Initially, the significance of that finding was unclear. ATP could be needed to either support active transport or make GTP to activate transducin.

To distinguish these roles of ATP, we supplied GTP analogs to the cytoplasm of ATP-depleted photoreceptors. The analogs were delivered into photoreceptors using staphylococcal $\alpha$-toxin, a polypeptide that makes pores that allow molecules $<2000 \mathrm{Da}$ to enter cells (Bhakdi et al., 1996; Otto-Bruc et al., 1998). Figure $1 \mathrm{~A}$ shows that $\alpha$-toxin allows entry of a fluorescently tagged nonhydrolyzable analog of GTP, BODIPY-GTP $\gamma \mathrm{S}$, but proteins such as rod transducin and recoverin do not escape via the $\alpha$-toxin pores. Green fluorescent protein (GFP) expressed in rods of a transgenic mouse also is retained in the cells treated with $\alpha$-toxin. BODIPYGTP $\gamma \mathrm{S}$ accumulates in photoreceptors when they are illuminated (Fig. $1 B$ ) evidently because of the rhodopsin-catalyzed exchange of endogenous GDP for the fluorescent nucleotide. Most importantly, BODIPY-GTP $\gamma S$ treatment in light induces dispersion of rod transducin $\alpha$ and $\beta$ subunits to all compartments of the photoreceptor cell even in ATP-depleted rods (Fig. 1C). This shows that transducin must be activated for redistribution to occur but that ATP and active transport are not required.

Nonfluorescent GTP or GTP $\gamma \mathrm{S}$ exerted a similar effect on rod transducin lo-
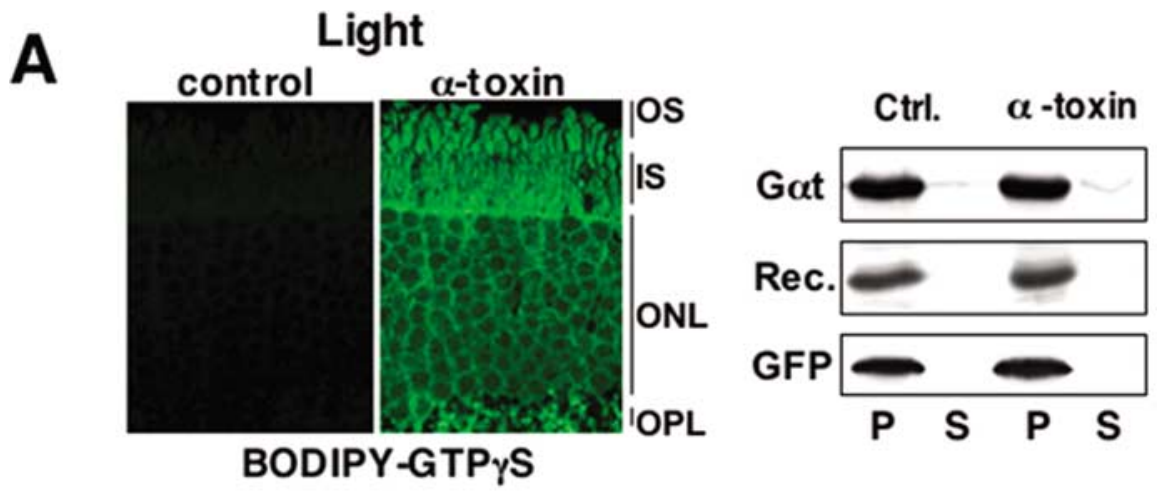

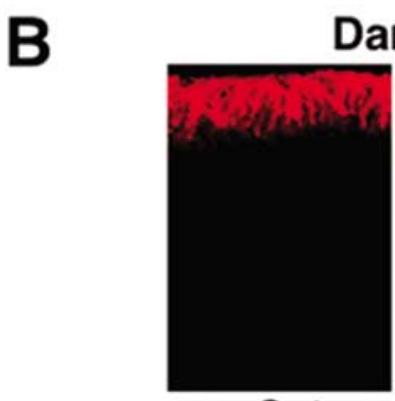

Got

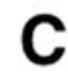

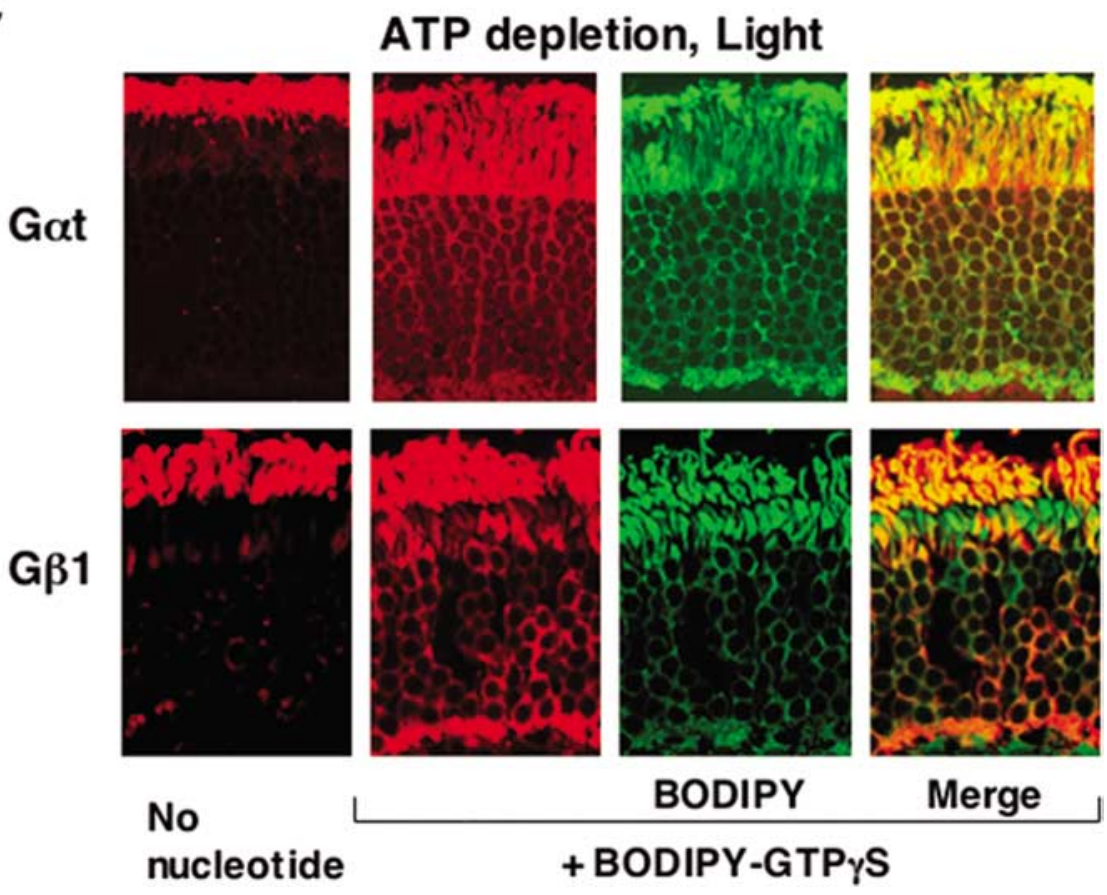

Figure 1. Light-dependent movement of rod transducin does not require ATP. A, Mouse retinas were incubated in DMEM in ambient light in the presence of $100 \mu \mathrm{m}$ BODIPY-GTP $\gamma$ S with or without $\alpha$-toxin, then fixed, sectioned, and visualized by fluorescence microscopy as described in Materials and Methods. A parallel set of retinas was tested for the potential loss of protein from the permeabilized cells. After the incubation with $\alpha$-toxin, the retinas were separated from the medium by centrifugation at $500 \times g$ for $30 \mathrm{~s}$. The supernatant $(\mathrm{S})$ containing the medium and the pellet $(\mathrm{P})$ were analyzed by Western blot using antibodies to $\mathrm{G} \alpha_{\mathrm{t}}(39 \mathrm{kDa}$ ) and recoverin $(24 \mathrm{kDa})$. To test the distribution of a marker cytosolic protein, GFP (27 kDa), retinas from GFPexpressing mice were also subjected to this assay. $\boldsymbol{B}$, Retinas were permeabilized with $\alpha$-toxin in the presence of BODIPY-GTP $\gamma$ S in the dark and then either illuminated or left in the dark for additional $30 \mathrm{~min}$. $\operatorname{Rod} \mathrm{G} \alpha_{\mathrm{t}}$ immunofluorescence is shown in red, and BODIPY fluorescence is green. C, Retinas were permeabilized with $\alpha$-toxin in glucose-free DMEM supplemented with $2 \mathrm{~mm}$ deoxyglucose and $5 \mathrm{~mm}$ KCN to deplete ATP. They were then incubated in the presence or absence of BODIPY-GTP $\gamma 5$ and subsequently illuminated for 30 min at 500 lux before fixing. Localization of rod transducin subunits and BODIPY-GTP $\gamma S$ was determined by fluorescence microscopy. 

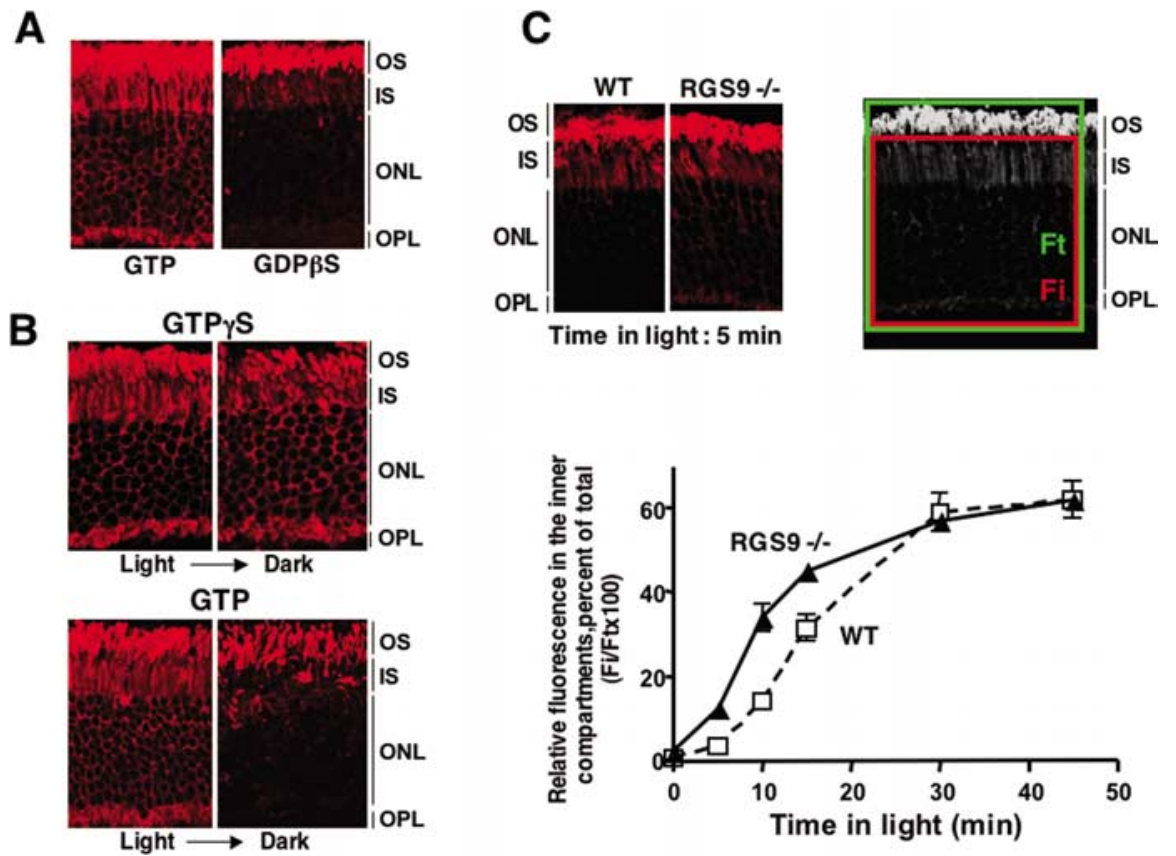

Figure 2. Relocalization of rod transducin is governed by GTP binding and hydrolysis. $\boldsymbol{A}$, Retinas were permeabilized in dark and incubated with $100 \mu \mathrm{M}$ GTP in glucose-free DMEM or $100 \mu \mathrm{M}$ GDP $\beta$ S in DMEM supplemented with $1 \mathrm{~mm}$ ATP. Retinas were then illuminated, fixed, and probed for $\operatorname{rod} \mathrm{G} \alpha_{\mathrm{t}}$ localization. $\boldsymbol{B}$, Two retinas were permeabilized in ambient light in the presence of GTP $\gamma S$ and another pair in the presence of GTP. One retina from each pair was subsequently transferred to the dark for additional $2 \mathrm{~h}$, whereas the control retina remained in light, after which they were fixed and analyzed for rod $\mathrm{G} \alpha_{\mathrm{t}}$ localization. These are representative of three independent experiments. $C$, The eyecups from dark-adapted wild-type and RGS9 knock-out (RGS9 ${ }^{-/-}$) mice were prepared under dim red light and transferred to 500 lux illumination. At the indicated times, the tissue was fixed and subsequently sliced and stained with anti-G $\alpha_{\mathrm{t}}$ antibody. The confocal images were analyzed as described in Materials and Methods. The two side-by-side images exemplify the difference between wild type (WT) and $R G S 9^{-/-}$mice at a single time point ( $5 \mathrm{~min}$ ) after the onset of light. The grayscale panel illustrates how the fluorescence in the inner compartments $\left(F_{\mathrm{i}}\right.$, red box $)$ and total fluorescence $\left(F_{\mathrm{t}}\right.$ green box) are selected to determine the relative distribution of $\mathrm{G} \alpha_{\mathrm{t}}\left(F_{\mathrm{i}} / F_{\mathrm{t}}\right)$. The LSM software color codes pixels outside the dynamic range of the camera, and so the images subjected to quantitative analysis remained within the linear range of fluorescent intensities. The graph below shows the mean $\pm S D F_{\mathrm{i}} / F_{\mathrm{t}}$ ratio for wild-type (white squares) and $R G S 9^{-/-}$ (black triangles) mice from three independent experiments.

calization (Fig. 2A,B), and GDP $\beta$ S blocked light-induced redistribution (Fig. $2 A$ ). Both GTP and GTP $\gamma S$ dispersed transducin from the OS in light. However, return to the OS after the subsequent incubation in darkness only occurred when GTP was used. GTP $\gamma S$ prevented resequestration of transducin in the OS in darkness (Fig. $2 \mathrm{~B}$ ). These results show that transducin must return to its GDP-bound state to become once again sequestered within the OS. To confirm this conclusion in live animals, we studied the kinetics of light-induced transducin redistribution in mice lacking RGS9, a member of regulator of G-protein signaling (RGS) family that acts as the GTPase-activating protein for transducin (He et al., 1998; Chen et al., 2000). We expected that activated transducin would accumulate faster than normal because the rate of its inactivation in $R G S 9^{-/-}$rods is slowed. Consistent with this, redistribution of rod transducin occurs faster in $R G S 9^{-/-}$rods than in wild-type retinas (Fig. $2 C$ ).

\section{Cone transducin in wild-type and genetically manipulated photoreceptors}

In agreement with previous observations (Elias et al., 2004; Kennedy et al., 2004; Coleman and Semple-Rowland, 2005), we found that light does not stimulate redistribution of cone transducin in cones (Fig. 3A). In retinas lacking the $\mathrm{Nrl}$ (neural retina leucine zipper) transcription factor $\left(\mathrm{Nrl}^{-/-}\right)$, all photoreceptors have morphological, biochemical, and physiological characteristics of cones (Mears et al., 2001; Daniele et al., 2005). We exam- ined cone transducin in $\mathrm{Nrl}^{-/-}$cones and found that it does not redistribute to inner compartments in light, similar to its behavior in wild-type cones (Fig. 3, compare $A, B)$. Cones express higher levels of RGS9 than rods (Cowan et al., 1998). Because RGS9 attenuates the relocalization of rod transducin (Fig. 2C), we hypothesized that the high level of RGS9 activity in cones might be responsible for the permanent sequestration of cone transducin in the OS of cones. However, the absence of RGS9 does not alter the localization of cone transducin in cones (Fig. 3C). Next, we tested whether the irreversible binding of GTP $\gamma \mathrm{S}$ can cause redistribution of cone transducin in cones. We found that GTP $\gamma S$ introduced into illuminated cones using $\alpha$-toxin does induce $\sim 10 \%$ of cone $\mathrm{G} \alpha_{\mathrm{t}}$ to move to the cone inner compartments (Fig. 3D).

The dramatic difference in spatial redistribution of cone and rod transducins could be determined by either the type of $\mathrm{G} \alpha_{\mathrm{t}}$ protein or the context of the cell in which it is expressed. To resolve this, we used Gnat2+,Gnat1 ${ }^{-/-}$(for guanine nucleotide binding protein, $\alpha$ transducin) mice in which cone $G \alpha_{t}$ is expressed in rods in a rod transducin-deficient background (Calvert et al., 2000). In striking contrast to its behavior in cones, cone $\mathrm{G} \alpha_{\mathrm{t}}$ undergoes light-dependent redistribution in Gnat2+,Gnat1 ${ }^{-1-}$ rods (Fig. 3E). Furthermore, the presence of cone $\mathrm{G} \alpha_{\mathrm{t}}$ in rods supports the light-dependent translocation of endogenous rod $\mathrm{G} \beta \gamma$. We conclude that the ability of transducin to change its distribution is determined by the cellular environment in the rod rather than by intrinsic properties of the $\alpha$ subunit.

\section{Activation of cone transducin}

Cones are less sensitive to light than rods, so the apparent inability of cone transducin to effectively redistribute in light could be explained by either inefficient activation of cone opsin or inefficient receptor-G-protein coupling. $\mathrm{Nrl}^{-/-}$retinas are dominated by UV opsin, so we used two types of light sources that have a strong UV output to ensure that cone transducin was fully activated in these experiments. One source was a $360 \mathrm{~nm}$ UV illuminator, and the other was direct sunlight. The UV illuminator was placed within $0.5 \mathrm{~cm}$ of the dissected eyecups. Its output peaked at $350 \pm 20 \mathrm{~nm}$, and its power was $1.5 \mathrm{~mW} / \mathrm{cm}^{2}$. This corresponds to $\sim 3 \times 10^{7} 350 \mathrm{~nm}$ photons per seconds per square micrometer. We evaluated the extent of bleaching of cone opsin using retinas from $\mathrm{Nrl}^{-1-}$ mice exposed to the UV illuminator. Because the spectral characteristics of UV opsin and all-trans retinal are very similar, it was necessary to evaluate the extent of UV pigment bleaching by analyzing retinoids by HPLC (Garwin and Saari, 2000). Approximately $75 \%$ of the 11 -cis-retinal chromophore in $\mathrm{Nrl}^{-/-}$retinas is converted into all-trans retinal, retinol, or retinyl esters after 5 min of exposure to either the UV illuminator or direct sunlight (Fig. 4A). We also evaluated the extent of cone pigment activation by measuring the extent to 
which the UV opsin C terminus is phosphorylated during its active lifetime. We measured the extent of phosphorylation of the UV opsin C terminus (Lee et al., 2002) after exposure to 1,5 , and $10 \mathrm{~min}$ of UV illumination or sunlight. With both sources of illumination, $30-35 \%$ of UV opsin was phosphorylated with one, two, or three phosphates in a steady state reached within 1 min exposure to the illumination (data not shown). These results show that, in the steady-state cycle of activation and inactivation in $\mathrm{Nrl}^{-/-}$cones, $75 \%$ of cone pigment is bleached and at least 30\% have undergone phosphorylation during its active lifetime. Cone transducin did not relocalize under any of the tested illumination conditions.

To establish whether the high level of cone opsin stimulation under our illumination conditions translates into efficient activation of cone transducin, we also directly evaluated cone transducin activation. We used GTP $\gamma S$ binding as an integrator of activation events to evaluate the extent of cone transducin activation under the same experimental conditions we used to determine cone transducin localization (Fig. 3C). Size-exclusion chromatography can be used to detect a reduction in the apparent molecular weight of a G-protein that indicates dissociation of activated $\mathrm{G} \alpha$ and $G \beta \gamma$ subunits. Activated cone transducin binds tightly to membranes (Fig. $5 D, E)$. Therefore, as with all other heterotrimeric G-proteins, except rod transducin, analysis of cone transducin by chromatography requires solubilization with mild detergent, typically $1 \%$ sodium cholate (Northup et al., 1983). Dissected retinas from $\mathrm{Nrl}^{-1-}$ mice were treated with $\alpha$-toxin in the presence of either GDP or GTP $\gamma \mathrm{S}$, exposed to direct sunlight, rinsed to remove unbound nucleotide, and then solubilized with cholate. We then analyzed the extracts by gel filtration. Our results showed a dramatic reduction in the apparent molecular weight of GTP $\gamma \mathrm{S}$-treated cone transducin characteristic of fully activated G-proteins (Fig. $5 B$ ). When the retinas were incubated with GTP $\gamma \mathrm{S}$ in the absence of $\alpha$-toxin or when they were incubated with GDP instead of GTP $\gamma \mathrm{S}$, or when they were incubated in darkness (data not shown), cone transducin remained heterotrimeric. In another set of experiments, we also compared the behavior of rod and cone transducin in isolated bovine OS membranes. The membranes were illuminated in the presence of either GDP or GTP $\gamma \mathrm{S}$, extracted with $1 \%$ cholate, and fractionated by gel filtration (Fig. $5 A$ ). Treatment with GTP $\gamma S$ caused a complete shift of the elution volume of both rod and cone transducin, demonstrating that both G-proteins bound GTP $\gamma$ S. The similarity of the results with permeabilized retinas and with isolated membranes indicates that, in both preparations, the bulk of cone transducin was stimulated to bind GTP $\gamma \mathrm{S}$.

We also used an independent method, a detergent-free pro-

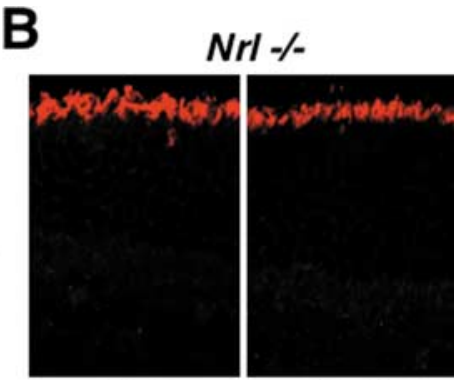

Dark

Light
RGS9 \%-

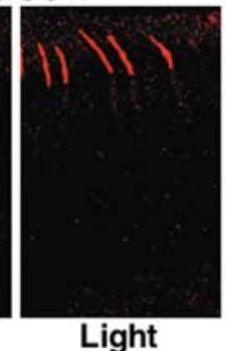

WT

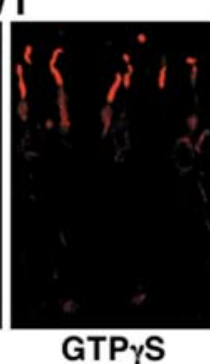

E

;Gnat 1-/-
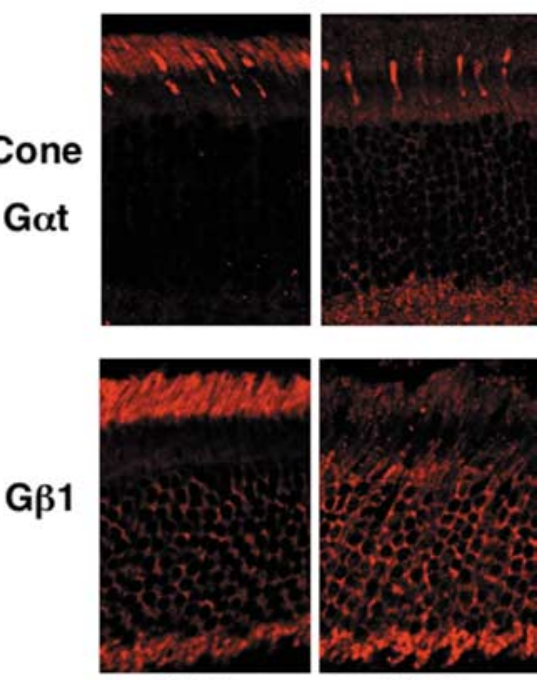

Dark

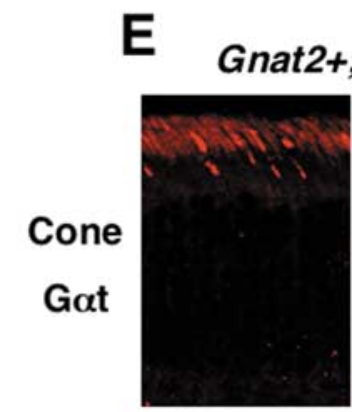

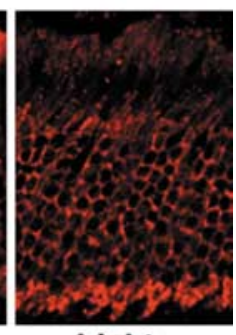

Light
Figure 3. Behavior of cone $\mathrm{G} \alpha_{\mathrm{t}}$ in cones and rods. $\boldsymbol{A}$, Wild-type mice were dark adapted for $12 \mathrm{~h}$ and killed, either immediately (Dark) or after an exposure to light (Light). Retinal sections were stained with the antibody against the $\alpha$ subunit of cone $G \alpha_{\mathrm{t}}$. The (light-adapted) sample. Shown are the results obtained during h illumination at ambient light (500 lux). An increase in light intensity to up to 100,000 lux (direct sunlight, dilated eyes) did no 列 GDP or GTP $\gamma$ (as in Figs. 1, 2) illuminated for $10 \mathrm{~min}$ at 5000 lux and then for $30 \mathrm{~min}$ at 500 lux and subsequently fixed and stained for cone $\mathrm{G} \alpha_{\mathrm{t}}$. Exposure of retinas to direct sunlight for up to $30 \mathrm{~min}$ or irradiation with $385 \mathrm{~nm}$ light source from a distance of $0.5 \mathrm{~cm}$ resulted in the similar distribution of cone $\mathrm{G} \alpha_{\mathrm{t}} . \boldsymbol{E}$, Localization of cone $\mathrm{G} \alpha_{\mathrm{t}}$ and rod $\mathrm{G} \beta$ subunit $\left(\mathrm{G} \beta_{1}\right)$ in the dark- and light-adapted (500 lux, $30 \mathrm{~min}$ ) Gnat2,$+ \mathrm{Gnat}^{-/-}$mice.

tease protection assay, to confirm that GTP $\gamma \mathrm{S}$ binds to cone transducin. Membranes from wild-type, $\mathrm{Nrl}^{-1-}$, or Gnat2+,Gnat ${ }^{-/-}$mice were incubated with GDP or GTP $\gamma S$ in light and subsequently treated with increasing concentrations of trypsin (Fig. 5C). Cone $\mathrm{G} \alpha_{\mathrm{t}}$ undergoes proteolytic fragmentation, consistent with it being bound to GTP $\gamma$ S.

Altogether, our analyses of cone opsin activation (Fig. 4) and the nucleotide-binding state of the G-protein (Fig. 5) show that cone transducin is fully activated in our experiments, yet it remains sequestered in the OS.

\section{Membrane association of rod and cone transducins}

We reasoned that, if rod transducin moves between the cell compartments by diffusion, the prerequisite for its exit from the OS would be release from membrane to cytosol. To account for the different behaviors of cone and rod transducins, rod transducin would dissociate from membranes more effectively than cone transducin. To test this idea, we compared the distributions of rod and cone transducins between soluble and particulate frac- 

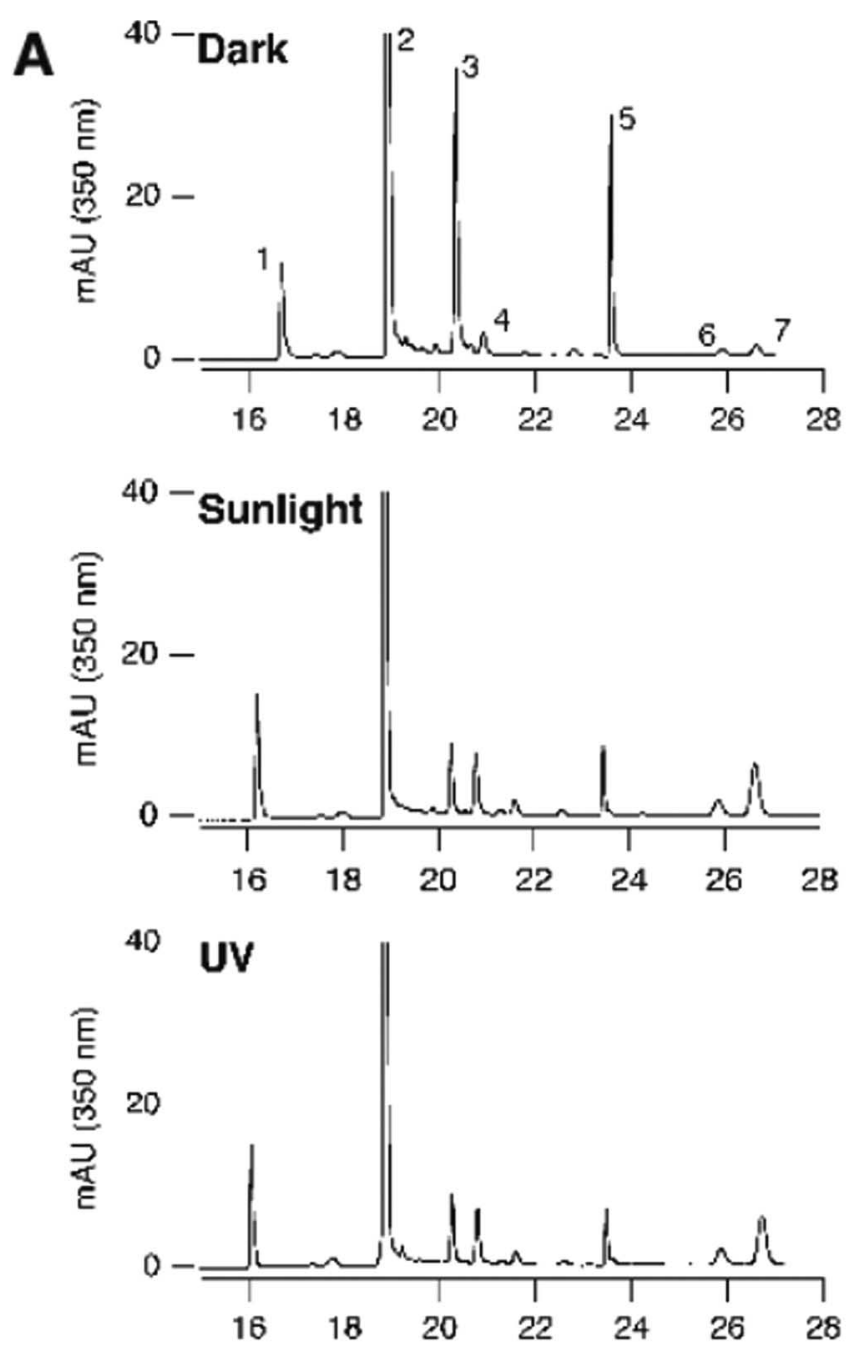

B

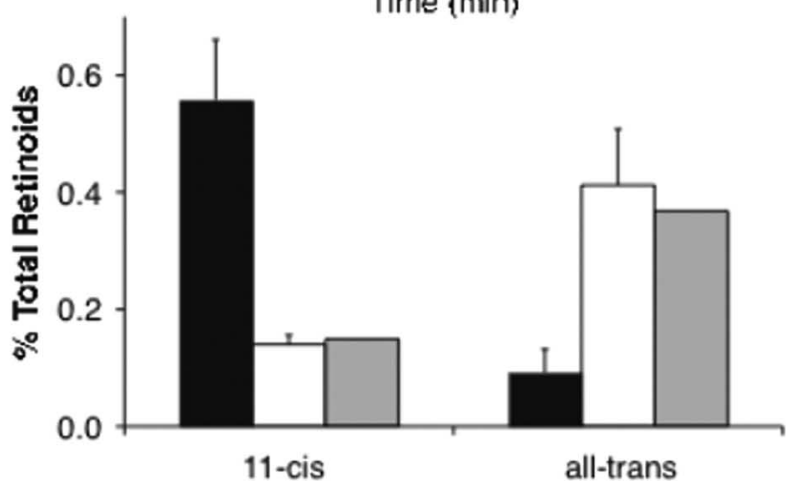

Figure 4. Retinoid analysis in $\mathrm{Nr}^{-/-}$retinas under UV or sunlight illumination. Nearly complete bleaching of cone visual pigment in $\mathrm{Nrl}^{-/-}$retinas. A, HPLC traces showing retinoid analyses from three conditions. Eyecups were prepared from dark-adapted mice and exposed to 5 min darkness, 5 min direct sunlight, or 5 min of illumination from a $350 \mathrm{~nm}$ UV lamp. Retinoids were extracted and analyzed by HPLC (Garwin and Saari, 2000). Note the significant reduction of peaks 3 and 5 (syn and anti-11-cis-retinal oxime) and the corresponding increases in all-trans retinoids (peaks $4,6,7$ ). Component 1 , retinyl esters; 2 , internal standard; 3, syn 11 -cis-retinal oxime; 4, syn all-trans-retinal oxime; 5, anti-11-cis-retinal oxime; 6, all-trans-retinol; 7, antiall-trans-retinal oxime. $\boldsymbol{B}$, Quantification of the results shown in $\boldsymbol{A}$. "11-cis-" refers to peaks 3 and 5 , and "all-trans" refers to peaks 4,6 , and 7. The black bars represent dark-adapted eyecups ( $n=2$ samples, four eyes each); the white bars represent eyecups illuminated with sunlight ( $n=2$ samples, 4 eyes each), and the gray bars represent eyecups illuminated with UV light ( $n=1$ sample, 4 eyes). tions from homogenates of either acutely cultured live mouse retinas (Fig. 5D) or purified OS membranes (Fig. 5E). As expected, rod transducin was solubilized readily from either whole retina or OS membranes by GTP $\gamma S$ and light. In contrast, the bulk of cone transducin remained in the particulate fractions in wild-type, $\mathrm{Nrl}^{-1-}$, and $\mathrm{RGS}^{-1-}$ photoreceptors (Fig. 5E). Importantly, we found that cone $\mathrm{G} \alpha_{\mathrm{t}}$ can be eluted readily by GTP $\gamma \mathrm{S}$ from membranes prepared from Gnat $2+$, Gnat $1^{-/-}$mice. This is consistent with the ability of cone transducin to redistribute when expressed in rods (Fig. 3E). Thus, the ability of cone transducin to leave the OS correlates with its ability to dissociate from membranes.

\section{$\mathrm{N}$-acylation of rod and cone $\mathrm{G} \alpha$ subunits}

Unlike other heterotrimeric G-proteins, which are acylated at their $\mathrm{N}$ termini with a myristoyl (C14:0) residue, rod transducin is acylated heterogeneously with C14:0, C14:1, C14:2, and C12:0 fatty acyl residues (Kokame et al., 1992; Neubert et al., 1992). We hypothesized that the difference between membrane association of cone and rod transducins could be caused by differences in their lipid modifications. To examine $\mathrm{N}$-acylation of rod and cone $\mathrm{G} \alpha$ subunits, we isolated them using SDS-PAGE, digested the excised protein bands with trypsin, and subjected the $\mathrm{N}$-terminal peptides to reverse-phase chromatography and tandem mass spectrometry (Fig. 6) (supplemental Fig. S1, available at www.jneurosci.org as supplemental material). We eluted rod transducin with light and GTP $\gamma \mathrm{S}$ and compared the fatty acid compositions of the soluble and membrane-bound forms of $\mathrm{G} \alpha_{\mathrm{t}}$. Both the soluble and membrane fractions contained all four species of rod $\mathrm{G} \alpha_{\mathrm{t}}: \mathrm{C} 14: 0, \mathrm{C} 14: 1, \mathrm{C} 14: 2$, and C12:0. There was only a slight enrichment of the membrane-bound $\mathrm{G} \alpha_{\mathrm{t}}$ with more hydrophobic acyl groups and only a slight enrichment of the soluble $\mathrm{G} \alpha_{\mathrm{t}}$ with the less hydrophobic species. To obtain sufficient amounts of cone $\mathrm{G} \alpha_{\mathrm{t}}$, we took advantage of its relatively high expression in the $\mathrm{Nrl}^{-/-}$and Gnat2+, Gnatl ${ }^{-/-}$animals. We found that cone $\mathrm{G} \alpha_{\mathrm{t}}$ is modified exclusively with $\mathrm{C} 14: 0 \mathrm{in} \mathrm{Nrl}^{-/-}$ mice. Surprisingly, cone $\mathrm{G} \alpha_{\mathrm{t}}$ in Gnat2+,Gnat1 ${ }^{-/-}$retinas, in which it can be solubilized, is also modified only by C14:0. These findings show that (1) the distribution of fatty acids is determined by the amino acid sequence of $\mathrm{G} \alpha_{\mathrm{t}}$ and not by its environment and (2) the membrane affinity of $\mathrm{G} \alpha_{\mathrm{t}}$ in cones versus rods is determined by a factor other than differential $\mathrm{N}$-myristoylation.

\section{Subunit dissociation facilitates dissociation of transducin from membranes and its dispersion throughout photoreceptor cells}

The tight association of cone $\mathrm{G} \alpha_{\mathrm{t}}$ with membranes could be attributable to its association with a cone-specific membrane protein. An obvious candidate for this protein would be RGS9, which is more abundant in cones than in rods (Cowan et al., 1998), but our finding that cone $\mathrm{G} \alpha_{\mathrm{t}}$ still associates with membranes in $R G S 9^{-1-}$ retinas (Fig. 5E) rules out this possibility. Another binding partner that plays a major role in membrane association of $\mathrm{G} \alpha_{\mathrm{t}}$ is the $\mathrm{G} \beta \gamma$ complex. To dissect the role of $\mathrm{G} \beta \gamma$ in membrane binding and redistribution of transducin, we performed a set of experiments in which dissociation of $\mathrm{G} \alpha$ and $\mathrm{G} \beta \gamma$ subunits was facilitated by synthetic myristoylated peptides, mSIRK and mSIGK. These novel reagents interfere with G-protein subunit association by binding directly to $G \beta$ at the same site in which $G \beta$ binds to $\mathrm{G} \alpha$ (Davis et al., 2005; Bonacci et al., 2006). The effects of these two peptides in our study were indistinguishable. Therefore, we will refer to either peptide as "mSIRK" in the following discussion. As a negative control in our studies, we used a mutant 
form of mSIRK, L9A, which has a single amino acid substitution and is ineffective at binding to $G \beta \gamma$.

Addition of mSIRK alone to permeabilized retinas induced dispersion of rod $\mathrm{G} \alpha_{\mathrm{t}}$ and $\mathrm{G} \beta \gamma$ even in the absence of nucleotides and in darkness (Fig. 7A). In contrast, mSIRK alone does not affect localization of cone $\mathrm{G} \alpha_{\mathrm{t}}$ in wild-type or $\mathrm{Nrl}^{-/-}$ mice in light or darkness. Remarkably, the combination of mSIRK and GTP $\gamma \mathrm{S}$ causes cone $\mathrm{G} \alpha_{\mathrm{t}}$ to disperse and equilibrate throughout the cytoplasm of wild-type (Fig. $7 \mathrm{~B}, \mathrm{C}$ ) and $\mathrm{Nrl}^{-/-}$(Fig. $7 E$ ) cones. Up to $60 \%$ of total cone $\mathrm{G} \alpha_{\mathrm{t}}$ immunofluorescence was detected in the inner compartments in the presence of GTP $\gamma \mathrm{S}$ and mSIRK, whereas GTP $\gamma S$ alone or in combination with L9A resulted in translocation of no more than $15 \%$ (Fig. 7 B, C). We also monitored the localization of the cone $\mathrm{G} \beta \gamma$ complex $\mathrm{G} \beta_{3} \gamma_{8}$ and found that $\mathrm{G} \beta_{3}$ remained in cone OS under all tested conditions, in both wild-type and $\mathrm{Nr}^{-1-}$ retinas (Fig. $7 D, E$ ).

Consistent with its effects on subcellular localization of rod and cone subunits, mSIRK promoted elution of $\operatorname{rod} \mathrm{G} \alpha$ and $\mathrm{G} \beta \gamma$ subunits from the membrane in the absence of GTP $\gamma \mathrm{S}$ and facilitated solubilization of cone $\mathrm{G} \alpha_{\mathrm{t}}$ but not cone $\mathrm{G} \beta_{3}$ (Fig. $8 A$ ). The effects of mSIRK on subunit dissociation of rod and cone G-proteins were consistent with the effects of this peptide on transducin localization in cells and membrane association. In the gel filtration assay, mSIRK caused the shift of at least $50 \%$ of the GDP-bound rod transducin toward the size corresponding to the dissociated subunits (Fig. $8 B$ ). In contrast, mSIRK caused only some broadening of the cone transducin peak, so that the bulk of cone transducin remained in its heterotrimeric form.

In summary, we found that (1) subunit dissociation, not GTP binding per se, is the event that determines localization of transducin and (2) the $\alpha$ and $\beta \gamma$ subunits of cone transducin associate with each more tightly than the subunits of rod transducin.

\section{Discussion}

This study shows that light-induced redistribution of transducin does not require active transport. It also answers two fundamental questions about transducin localization: (1) why does the distribution of transducin in rods change in light versus darkness?, and (2) why does the distribution of transducin in cones not depend on light?

Three experimental approaches were key to this study. (1) To deplete photoreceptors of energy, we incubated retinas without rod and cone $G \alpha$ subunits.
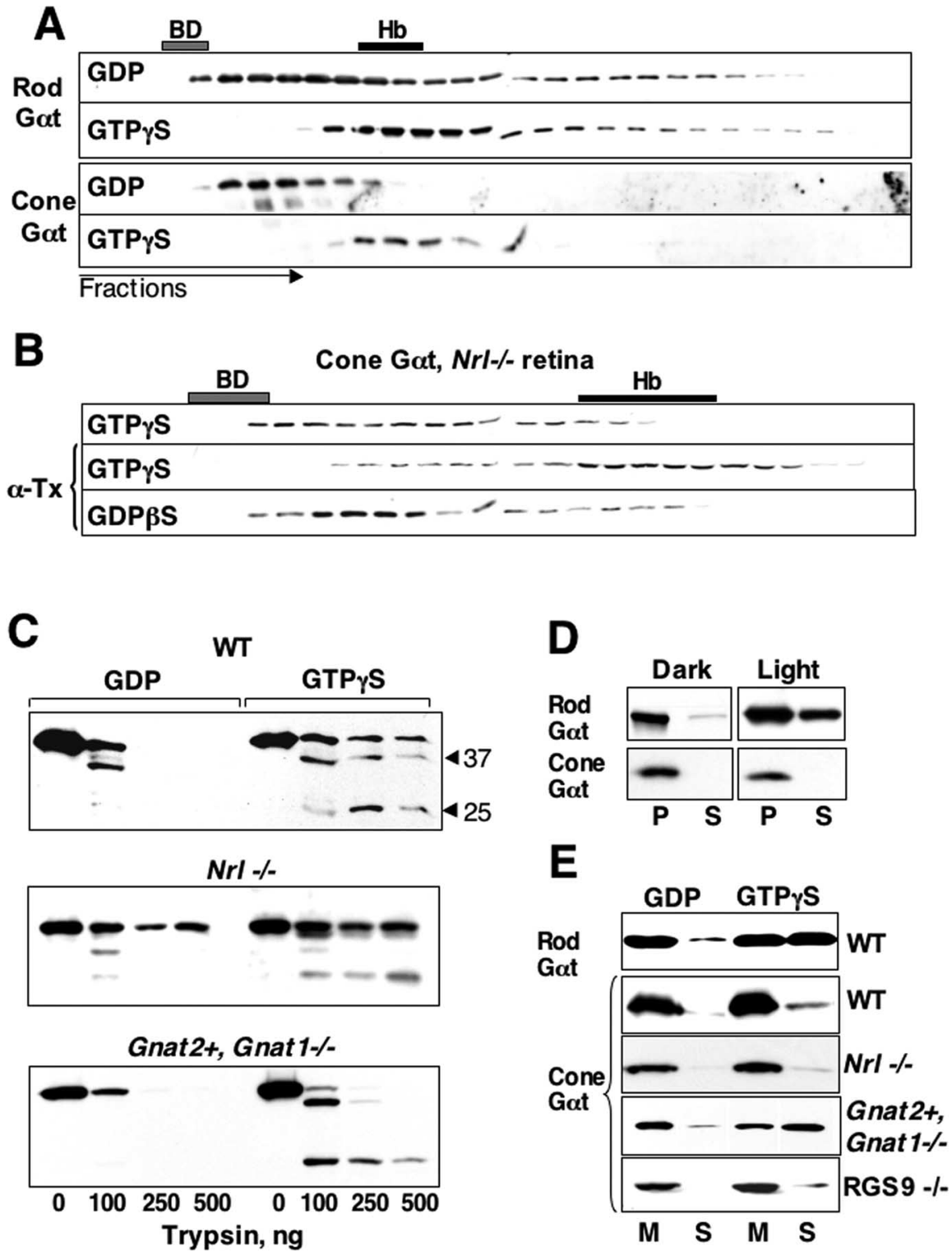

Figure 5. Cone transducin binds GTP $\gamma$ S but does not dissociate from the membranes. $\boldsymbol{A}$, Bovine OS membranes were incubated in light with GDP or GTP $\gamma S$ and solubilized with $1 \%$ sodium cholate. Blue dextran (BD) and hemoglobin (Hb; $60 \mathrm{kDa}$ as the tetramer) were added to the extracts before fractionation on a $1 \times 25 \mathrm{~cm}$ Superdex 75 size exclusion column. The fractions were probed for rod and cone $\mathrm{G} \alpha_{\mathrm{t}}$ subunits. Note that the Stokes radius of the $\mathrm{G}$-proteins is increased relative to the theoretical size because of the bound cholate. $\boldsymbol{B}$, Freshly dissected retinas from $\mathrm{Nrl}^{-/-}$mice were permeabilized with $\alpha$-toxin $(\alpha$-Tx) in the dark in the presence of GTP $\gamma S$ or GDP $\beta$, then illuminated for 5 min at 1000 lux, and rinsed in $5 \mathrm{ml}$ of medium to wash out free nucleotide. In a control testing the integrity of nonpermeabilized cell membranes, $\alpha$-toxin was omitted from the media before the subsequent incubation with GTP $\gamma$ S. The retinas were then homogenized, solubilized with $1 \%$ cholate, and fractionated on a $0.4 \times 24 \mathrm{~cm}$ Superdex 75 column. C, Limited trypsinolysis assay. The OS membranes from wild-type (WT), $\mathrm{Nr}^{-1-}$, and Gnat2,$+ \mathrm{Gnat1}^{-/-}$mice were incubated with the increasing amounts of trypsin, in the presence of GDP or GTP $\gamma \mathrm{S}$. The reaction was stopped by addition of SDS, and the samples were analyzed by Western blot. $\boldsymbol{D}$, Whole retinas were dissected from darkadapted wild-type mice and either kept in the dark or illuminated. The retinas were homogenized and centrifuged, and the pellet $(P)$ and supernatant $(S)$ were probed with antibodies for rod and cone $G \alpha$ subunits. Shown is the result of a 15 min illumination at 1000 lux; the exposure of the retinas to direct sunlight resulted in the same distribution of cone and rod transducins. $E, 0 S$ membranes were isolated in the dark from wild-type (WT), $\mathrm{NrI}^{-/-}, \mathrm{Gnat} 2+, \mathrm{Gnat}^{-/-}$, and $\mathrm{RGS}^{-1-}$ mice. Membrane suspension was illuminated at 1000 lux by a fluorescent lamp or by direct sunlight in the presence of GDP or GTP $\gamma S$ and then centrifuged to obtain membrane $(M)$ and soluble $(S)$ fractions. The pellet $(P)$ and supernatant $(S)$ were probed with antibodies for

glucose and with KCN. This treatment causes loss of essentially all ATP in the retina, and it blocks rhodopsin phosphorylation (Nair et al., 2005a), a biochemical reaction with a low $K_{\mathrm{m}}(\sim 2 \mu \mathrm{M})$ for ATP (Palczewski et al., 1988). (2) We permeabilized photorecep- 
A

\section{WT}

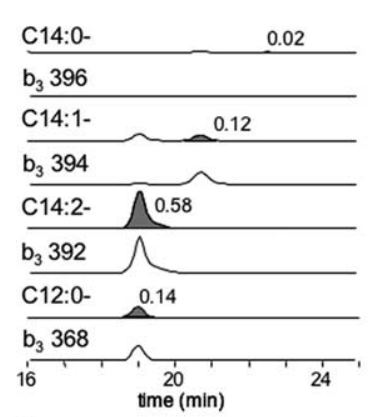

B

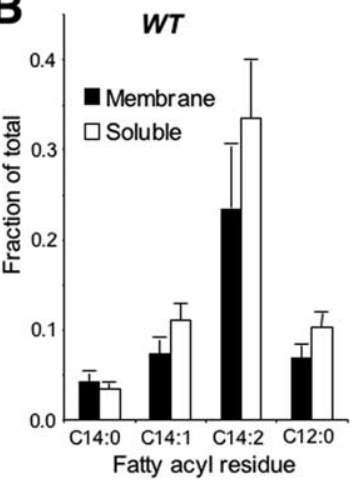

NrI-/-

-GSGISAEDK
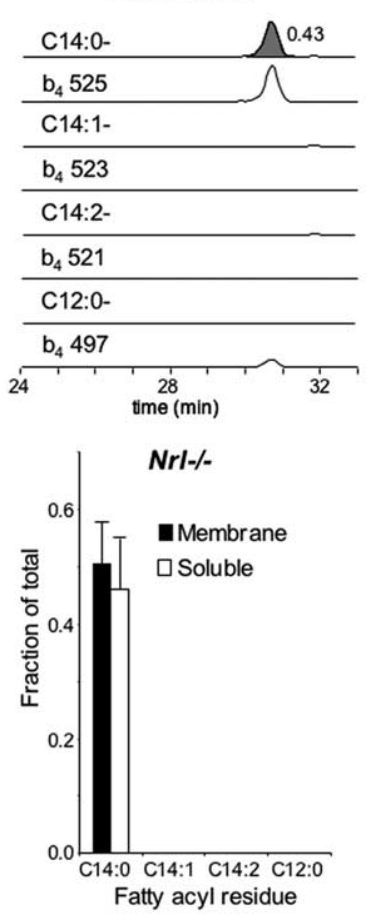

Gnat2+; Gnat1-/-GSGISAEDK

\begin{tabular}{l} 
C14:0- \\
\hline $\mathrm{b}_{4} 525$ \\
\hline $\mathrm{C} 14: 1-$ \\
\hline $\mathrm{b}_{4} 523$ \\
\hline $\mathrm{C} 14: 2-$ \\
\hline $\mathrm{b}_{4} 521$ \\
\hline $\mathrm{C} 12: 0-$ \\
\hline $\mathrm{b}_{4} 497 \quad{ }_{\text {time(min) }}^{0.55}$ \\
\hline 36
\end{tabular}

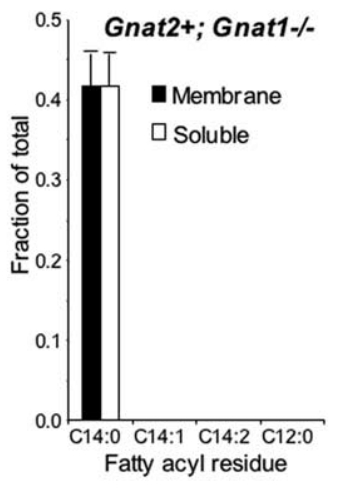

Figure 6. Distinct $\mathrm{N}$-acylation of rod and cone transducin $\alpha$ subunits. OS membranes were isolated from dark-adapted wildtype (WT), $\mathrm{Nr}^{-/-}$, and Gnat2+, Gnat $1^{-/-}$mice, treated with $100 \mu \mathrm{M} \mathrm{GTP} \gamma \mathrm{S}$, and centrifuged to obtain the soluble and membrane fractions. The fractions were resolved on SDS-PAGE and stained with Coomassie blue. The bands corresponding to rod and cone $G \alpha$ t were excised, and the slices were digested with trypsin and extracted. The resulting mixture of peptides was analyzed by HPLC and mass spectrometry to determine the amount of the $\mathrm{N}$-acylated $\mathrm{N}$-terminal peptides. $\mathrm{A}$, lon chromatograms monitoring narrow mass windows ( $1 \mathrm{Da}$ ) corresponding to rod and/or cone transducin $\mathrm{N}$-terminal peptides with fatty acyl residues from the soluble fractions obtained from wild-type, $\mathrm{Nrl}^{-/-}$, and $\mathrm{Gnat2}+, \mathrm{Gnat1}^{-/-}$retinas, respectively. The peptides were detected in their singly charged state with the following mass-to-charge ratio: rod $\mathrm{G} \alpha_{\mathrm{t}}$ C14:0-GAGASAEEK, 1029.5; C14:1GAGASAEEK, 1027.5; C14:2-GAGASAEEK, 1025.4; C12:0-GAGASAEEK, 1001.5; cone G $\alpha_{t}$ C14:0-GSGISAEDK, 1072.5; (14:1GSGISAEDK, 1070.5; C14:2-GSGISAEDK, 1068.5; C12:0-GSGISAEDK, 1044.5. Each peptide was sequenced by CID to confirm its identity (ion chromatograms for $b_{3}$ or $b_{4}$ shown above). The $y$-axis for each chromatogram represents the relative abundance of each peak and is normalized to the amplitude of the maximum signal in the whole ion chromatogram (molecular and fragment ion chromatograms have individual maxima). The $x$-axis represents the elution time from the $(18$ reversed-phase column. The numbers to the right of each peak represent the relative fraction of each species calculated by integrating the area under each peak. $B$, The four fatty acyl N-terminal transducin peptides in membrane and soluble fractions from wild-type, $\mathrm{Nr}^{-/-}$, and Gnat2,+ Gnat $^{-/-}$retina were quantified by integrating the areas under peaks corresponding to the peptides. The level of each species is expressed as the fraction of the rod or cone $G \alpha$ peptide detected in the membrane $(M)$ or soluble $(S)$ fractions, respectively. Each data point is the average of at least four separate determinations. The error bars represent SD.

tors with $\alpha$-toxin. $\alpha$-Toxin-treated cells take up nucleotides (BODIPY-GTP $\gamma \mathrm{S}$ ) and retain proteins (transducin and recoverin) (Fig. 1). (3) To promote dissociation of transducin subunits in photoreceptors, we used mSIRK, a small peptide that competes with $\mathrm{G} \alpha$ for a binding site on $\mathrm{G} \beta$ (Figs. 7, 8).

\section{The dissociate/disperse model}

Classic in vitro studies of phototransduction suggest a simple explanation for the light-dependent localization of transducin in rods. Activation lowers the affinity of transducin $\alpha$ for $\beta \gamma$ (Fung et al., 1981), and it weakens the affinity of rod transducin for membranes (Kuhn, 1980). Recent evidence indicates transducin subunits also dissociate under physiological conditions (Sokolov et al., 2002).

It is reasonable to propose (Calvert et al., 2006) a link between the dissociation state of transducin and its distribution. Immediately after activation, the subunits dissociate, leave OS membranes, and enter the cytoplasm. Cytosolic proteins equilibrate quickly throughout all compartments of a photoreceptor (Peet et al., 2004; Nair et al., 2005). If all of the transducin in a rod is activated, e.g., in photoreceptors containing GTP $\gamma$ S, its subunits will dissociate and disperse so that cytoplasmic concentrations of transducin in all compartments of the cell become equal.

The aim of our study was to test this hypothesis. We simplified the system by stabilizing either the active or inactive forms of transducin using specific guanine nucleotides introduced into photoreceptors permeabilized by $\alpha$-toxin. GTP $\gamma S$ stabilizes the activated state, and GDP $\beta$ S stabilizes the inactive state. GTP $\gamma S$ causes transducin to disperse from the OS (Figs. 1,2 ), and GDP $\beta$ S keeps it sequestered in the OS (Fig. $2 A$ ). These findings provide simple and direct experimental support for the dissociate/disperse hypothesis. They also provided us with an experimental framework to investigate the reason for the different localization of activated transducin in rods and cones.

\section{Subunit association, membrane binding, and localization}

Transducin localization in photoreceptors correlates with its membrane affinity. Rod transducin readily detaches from membranes (Figs. 5E, 8A) and disperses throughout the cell. Cone transducin in normal and $\mathrm{Nrl}^{-/-}$cones remains bound to membranes (Fig. 5D,E, 8A), and it stays mostly in the OS (Figs. 3, 7), even when fully activated (Figs. 4, 5A-C). The different membrane affinities and distributions of transducins in rods versus cones could reflect differences inherent in either the type of G-protein or the type of cell in which it is expressed. To resolve this, we examined membrane binding and localization of cone $\mathrm{G} \alpha_{\mathrm{t}}$ expressed in rods in place of $\operatorname{rod} \mathrm{G} \alpha_{\mathrm{t}}$. We found that activated cone $\mathrm{G} \alpha_{\mathrm{t}}$ in rods has a weak affinity for membranes, and it disperses throughout the rod cell when activated (Figs. 3E, 5E). Therefore, the ability to disperse transducin is a property of the cellular environment, not the type of $G \alpha_{\mathrm{t}}$. What could be the factors responsible for the strikingly different behavior of $\mathrm{G} \alpha_{\mathrm{t}}$ in rods versus in cones?

Lipid modification of $G \alpha_{t}$

The affinity of a G-protein for membranes is influenced by $\mathrm{N}$-acylation of its $\alpha$ subunit (Bigay et al., 1994; Wang et al., 1999; Chen and Manning, 2001). Rod transducin is modified by a mixture of fatty acyl residues, including C14:2, C14:1, and C12:0. We hypothesized that $\mathrm{G} \alpha_{\mathrm{t}}$ in cones is modified only with the more hydrophobic C14:0, but, when expressed in rods, it is acylated with the less hydrophobic residues. Indeed, cone $\mathrm{G}_{\mathrm{t}}$ in $\mathrm{Nr}{ }^{-/-}$ cones is modified exclusively by C14:0 (Fig. 6) (supplemental Fig. S1, available at www.jneurosci.org as supplemental material). This appeared to be a reasonable explanation for the enhanced 
membrane affinity of activated cone $\mathrm{G} \alpha_{\mathrm{t}}$. However, two findings argue against that explanation. First, C14:0 rod transducin also partitions to the cytosol and is only slightly enriched in membranes (Fig. 6). Second, cone $\mathrm{G} \alpha_{\mathrm{t}}$ is still modified exclusively by C14:0 when expressed in rods (Figs. 3, 5, 6). These findings show that the type of $\mathrm{N}$-terminal acylation on $\mathrm{G} \alpha_{\mathrm{t}}$ is a characteristic of the type of transducin, and it does not determine either the affinity of $\mathrm{G} \alpha_{\mathrm{t}}$ for membranes or the localization of $\mathrm{G} \alpha$.

Prenylation of $G \gamma$ subunits

Prenylation of $\mathrm{G} \gamma$ influences the localization of $\operatorname{rod} \mathrm{G} \beta \gamma$. Replacing the farnesyl (C15) modification normally present at the $\mathrm{C}$ terminus of the rod $\mathrm{G} \gamma_{1}$ with a geranylgeranyl (C20) residue prevents lightinduced dispersal of $\mathrm{G} \beta_{1} \gamma_{1}$ from the OS (Kassai et al., 2005). However, the type of modification on $\mathrm{G} \gamma_{1}$ does not affect the distribution of rod G $\alpha_{\mathrm{t}}$ in rods (Kassai et al., 2005). It is, therefore, unlikely that differences in prenylation of rod $\mathrm{G} \gamma_{1}$ and cone $\mathrm{G} \gamma_{8}$ are responsible for the different distributions of cone $\mathrm{G} \alpha_{\mathrm{t}}$ when expressed in rods versus when it is expressed in cones.

\section{The type of $G \beta \gamma$ complex}

The G $\beta \gamma$ complex in rods is assembled from $G \beta_{1}$ and $G \gamma_{1}$. In cones, it is $G \beta_{3}$ and $\mathrm{G} \gamma_{8}$ (Fung et al., 1992; Ong et al., 1995). A careful analysis of the data in Figures 7 and 8 reveals a relationship between localization of activated $\mathrm{G} \alpha_{\mathrm{t}}$ and its affinity for $\beta \gamma$. When either rod or cone $\mathrm{G} \alpha_{\mathrm{t}}$ is fully and stably activated by GTP $\gamma$ S, an equilibrium must occur in which the cytosolic concentration of soluble $\mathrm{G} \alpha_{\mathrm{t}}$ is equal in all compartments of the photoreceptor cell (Figs. 1-3). This equilibrium is obvious in rods (Fig. $7 C$ ), but, in cones under these conditions, there is an excess of cone $\mathrm{G} \alpha_{\mathrm{t}}$ in the outer segment (Fig. 7C). We hypothesized that this excess must represent a complex of GTP $\gamma S$-activated cone $\mathrm{G} \alpha_{\mathrm{t}}$ with $\mathrm{G} \beta_{3} \gamma_{8}$ bound to membranes (Fig. 7D). To test this, we used mSIRK, a peptide that promotes G-protein dissociation (Smrcka and Scott, 2002; Davis et al., 2005). If the excess cone $\mathrm{G} \alpha_{\mathrm{t}}$ in the OS is associated with $\mathrm{G} \beta \gamma$, mSIRK, a peptide that competes with $\mathrm{G} \alpha$ for binding to $G \beta \gamma$, would disrupt the complex and $\mathrm{G} \alpha_{\mathrm{t}}$ would disperse. If excess cone $\mathrm{G} \alpha_{\mathrm{t}}$ were in the OS for a different reason, it would not be affected by mSIRK. mSIRK does disperse excess cone $\mathrm{G} \alpha_{\mathrm{t}}$ from the OS

(Fig. 7 B, C,E). Therefore, the excess cone $\mathrm{G} \alpha_{\mathrm{t}}$ in the OS does represent the fraction of GTP $\gamma$ S-bound cone $\mathrm{G} \alpha_{\mathrm{t}}$ associated with $\mathrm{G} \beta_{3} \gamma_{8}$ (Figs. $7 D, 8 A$ ). In rods, the equilibrium state is different: nearly all $\mathrm{G} \alpha_{\mathrm{t}}-\mathrm{GTP} \gamma \mathrm{S}$ is dissociated from $\mathrm{G} \beta_{1} \gamma_{1}$ so the subunits are dispersed throughout the rod. Consistent with this, mSIRK does not affect the distribution of activated rod $\mathrm{G} \alpha_{\mathrm{t}}$ (Fig. 7C).

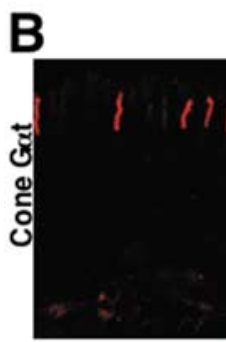

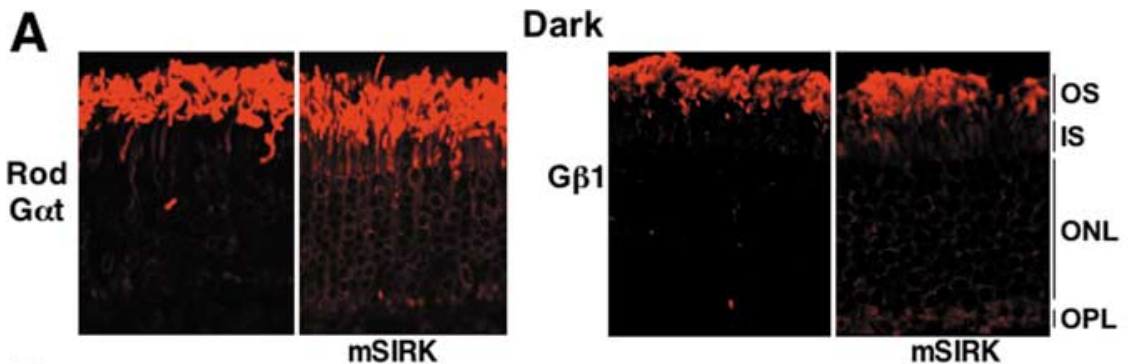

MSIRK

Light
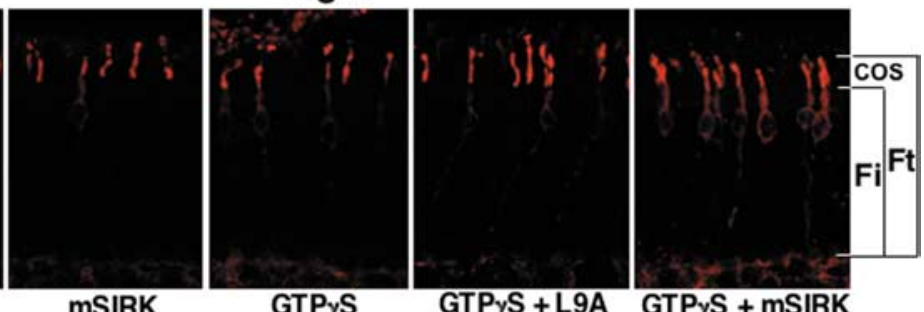

mSIRK

GTPYS

GTPYS + L9A

GTP $\gamma$ S + mSIRK

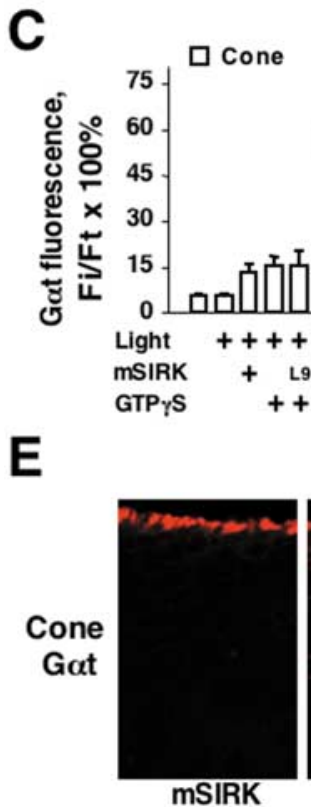

Figure 7. Translocation of rod and cone transducins is facilitated by the synthetic $G \beta$-binding peptide mSIRK. $A$, Dark-adapted retinas were permeabilized with $\alpha$-toxin and incubated in the dark in the presence or absence of $50 \mu \mathrm{m}$ mSIRK. After $1 \mathrm{~h}$, the retinas were fixed, and the localization of $\operatorname{rod} \mathrm{G} \alpha_{\mathrm{t}}$ and $\mathrm{G} \beta_{1}$ was determined. $\boldsymbol{B}$, Dark-adapted retinas were permeabilized with $\alpha$-toxin and treated with $50 \mu \mathrm{m}$ mSIRK or its inactive mutant (L9A) peptide in the presence or absence of $100 \mu \mathrm{M} \mathrm{GTP} \gamma \mathrm{S}$. Retinas were then exposed to sunlight for 15 min, fixed, sectioned, and stained with antibodies against cone $G \alpha_{\mathrm{t}}$. C, Quantification of the data from a series of experiments including one shown in $B$. Rod or cone $G \alpha_{t}$ immunofluorescence in the entire photoreceptor $\left(F_{t}\right)$ and immunofluorescence from the inner compartments $\left(F_{\mathrm{i}}\right)$ were determined as described in Figure 2 and Materials and Methods. The average $F_{\mathrm{i}} / F_{\mathrm{t}}$ ratio (mean $\pm S D$ ) in each experiment was determined within three areas of the retina. The data were collected in at least six independent batches of retinas (groups of mice). Retinas were dissected under dim red light and permeabilized in the presence of GTP $\gamma S$, mSIRK, L9A mutant, or mSIRK with GTP $\gamma S$ as indicated. For L9A plus GTP $\gamma S, n=3$. The concentration of $\mathrm{mSIRK}$ or L9A was $50 \mu \mathrm{m}$. Light intensities varied from 500 lux to direct sunlight, providing identical results. Control permeabilized retinas were kept in the dark. $\boldsymbol{D}$, Localization of cone $\mathrm{G} \beta \gamma\left(\mathrm{G} \beta_{3}\right.$ immunoreactivity) in permeabilized wild-type mouse retinas treated with mSIRK, L9 with GTP $\gamma$ S, and mSIRK with GTP $\gamma$ S, in light. This is representative of three independent experiments. $\boldsymbol{E}$, Retinas of $\mathrm{Nrl}^{-/-}$mice were permeabilized and treated with mSIRK or mSIRK with GTP $\gamma S$, in light (1000 lux or direct sunlight for 5 or 30 min produced identical results). Localization of cone $G \alpha_{t}$ and $G \beta_{3}$ was determined by immunofluorescence microscopy.

\section{Transducin redistribution}

In darkness, the membrane-rich OS of rods and cones retain nearly all of the inactive heterotrimeric transducin (supplemental Fig. S4, available at www.jneurosci.org as supplemental material). Light stimulates transducin to bind GTP and assume its active conformation. The affinity of activated $\operatorname{rod} \mathrm{G} \alpha_{\mathrm{t}}$ for its 

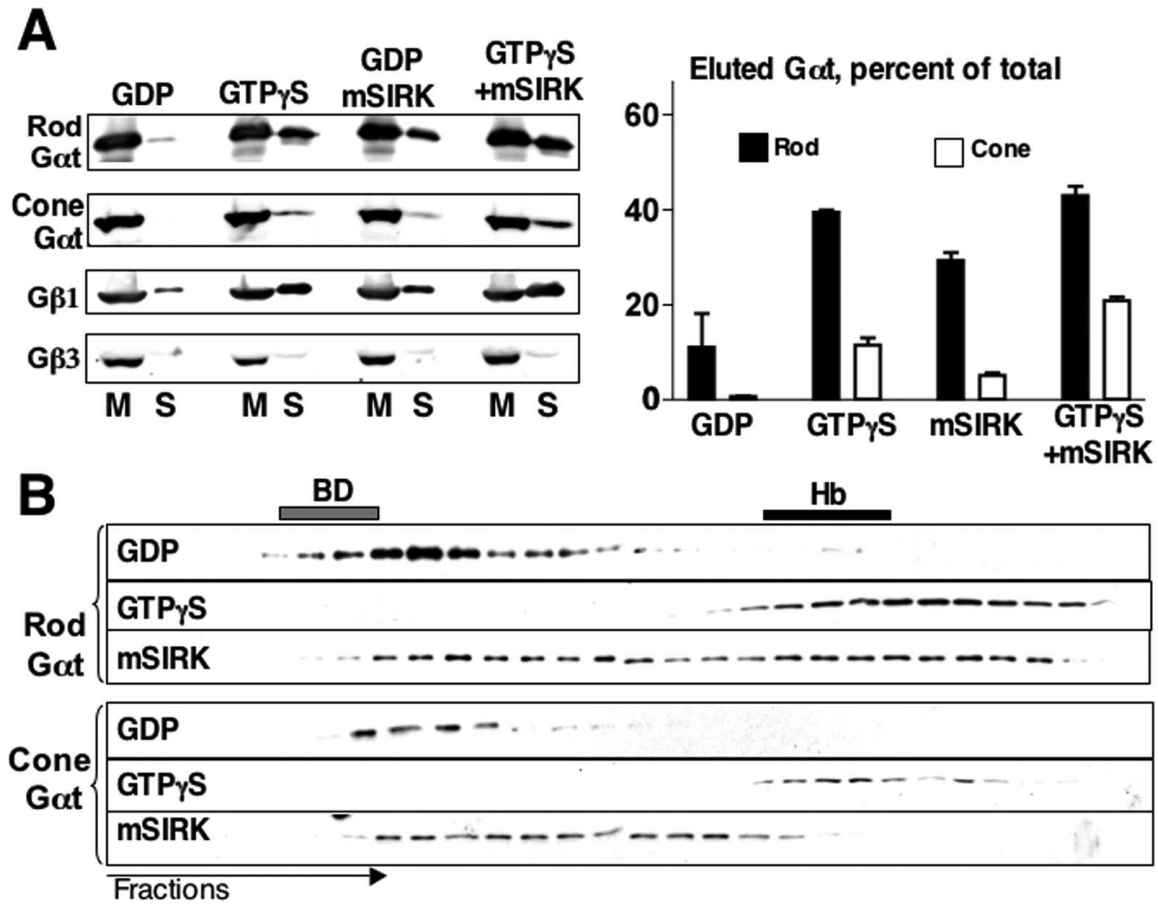

Figure 8. Subunit dissociation underlies the difference between rod and cone transducins in membrane release and dispersion from OS. $A, 0 S$ membranes isolated from dark-adapted retinas were resuspended in a buffer containing $100 \mu \mathrm{m}$ GDP, GTP $\gamma S, 100$ $\mu \mathrm{M}$ mSIRK, or the mixture of mSIRK and GTP $\gamma$ S. After a 10 min incubation at room temperature in light (1000 lux or sunlight), the suspension was centrifuged to obtain the supernatant $(S)$ and membrane $(M)$ fractions. These samples were analyzed by Western blot with antibodies against rod and cone $G \alpha_{t}, G \beta_{1}$, and $G \beta_{3}$ subunits. The bar graph shows the amount of solubilized $G \alpha_{t^{\prime}}$ as percentage of total, as mean \pm SD from at least three independent experiments, in which the Western blots were scanned and analyzed by Scion (Frederick, MD) software. B, Bovine 0 S membranes were treated with $50 \mu \mathrm{m} \mathrm{mSIRK}$ and solubilized with $1 \%$ cholate. Fifty microliters of the extract were resolved by gel filtration on a $0.4 \times 25 \mathrm{~cm}$ Superdex 75 column, which was preequilibrated with the buffer containing $25 \mu \mathrm{m}$ mSIRK. The distribution of rod and cone $G \alpha_{\mathrm{t}}$ in the collected fractions was determined by Western blot. The extracts from GDP- and GTP $\gamma$ S-treated membranes were resolved on the same column to determine the location of the heterotrimers and dissociated $\mathrm{G} \alpha$ subunits, respectively. BD, Blue dextran; $\mathrm{Hb}$, hemoglobin. al., 2005b), and cytoskeletal elements (Peterson et al., 2005), may act as diffusion barriers that impede relocalization.

\section{G-protein dissociation}

Dissociation of rod transducin has served for many years as a general model for G-protein activation (Gilman, 1987; Levitzki and Klein, 2002). We have shown that the propensity of activated cone transducin to dissociate is so low that a significant proportion of it remains heterotrimeric and bound to membranes even when it is fully activated in cone cells. We infer that many G-proteins, like cone transducin, remain associated during activation in their cellular environment.

\section{References}

Bhakdi S, Bayley H, Valeva A, Walev I, Walker B, Kehoe M, Palmer M (1996) Staphylococcal alpha-toxin, streptolysin-O, and Escherichia coli hemolysin: prototypes of pore-forming bacterial cytolysins. Arch Microbiol 165:73-79.

Bigay J, Faurobert E, Franco M, Chabre M (1994) Roles of lipid modifications of transducin subunits in their GDP-dependent association and membrane binding. Biochemistry 33:14081-14090.

Bonacci TM, Mathews JL, Yuan C, Lehmann DM, Malik S, Wu D, Font JL, Bidlack JM, Smrcka AV (2006) Differential targeting of Gbetagamma-subunit signaling with small molecules. Science 312:443-446.

Calvert PD, Krasnoperova NV, Lyubarsky AL, Isayama T, Nicolo M, Kosaras B, Wong G, Gannon KS, Margolskee RF, Sidman RL, Pugh Jr EN, Makino CL, Lem J (2000) Phototransduction in transgenic mice after targeted deletion of the rod transducin alpha-subunit. Proc Natl Acad Sci USA 97:13913-13918.

partner, $\mathrm{G} \beta_{1} \gamma_{1}$, is weak. Dissociated rod $\mathrm{G} \alpha_{\mathrm{t}}$ and $\mathrm{G} \beta \gamma$ subunits have a low affinity for membranes so they disperse throughout the cytoplasm of all compartments of the rod. The affinity of activated cone $\mathrm{G} \alpha_{\mathrm{t}}$ for its partner $\mathrm{G} \beta_{3} \gamma_{8}$ is strong. Activated cone transducin essentially remains heterotrimeric. It is retained in the OS because the heterotrimer has a high affinity for membranes and because $\mathrm{G} \beta_{3} \gamma_{8}$ itself has a high membrane affinity.

In a photoreceptor operating in constant light under physiological conditions, activation of transducin is neither complete nor stable. Instead of equilibrium, a steady state is established throughout the photoreceptor. The subcellular distribution of rod G-protein in this steady state and the rate at which this state is reached depend on relative rates of activation, deactivation, and diffusion. Impairment of GTP hydrolysis, by GTP $\gamma \mathrm{S}$ binding, by RGS9 gene inactivation, or by the Q200L mutation in $\mathrm{G} \alpha_{\mathrm{t}}$ (Kerov et al., 2005a), favors the GTP-bound dissociated and dispersed state. Accordingly, GDP $\beta S$ (Fig. $2 A$ ) or overexpression of RGS9 (Lobanova et al., 2007) shifts transducin toward the associated state, which concentrates in the OS. Transducin migration throughout the rod cell requires tens of minutes (Sokolov et al., 2002; Elias et al., 2004), which is much slower than unimpeded diffusion of a soluble protein in rods (Nair et al., 2005a) and cones (supplemental Fig. S3, available at www.jneurosci.org as supplemental material). Transducin binding partners, such as phosducin (Sokolov et al., 2004), centrin (Wolfrum et al., 2002), Leu-Gly-Asn repeat (LGN) protein (Kerov et al., 2005b; Nair et
Calvert PD, Strissel KJ, Schiesser WE, Pugh Jr EN, Arshavsky VY (2006) Light-driven translocation of signaling proteins in vertebrate photoreceptors. Trends Cell Biol 16:560-568.

Chen CA, Manning DR (2001) Regulation of G proteins by covalent modification. Oncogene 20:1643-1652.

Chen CK, Burns ME, He W, Wensel TG, Baylor DA, Simon MI (2000) Slowed recovery of rod photoresponse in mice lacking the GTPase accelerating protein RGS9-1. Nature 403:557-560.

Coleman JE, Semple-Rowland SL (2005) GC1 deletion prevents lightdependent arrestin translocation in mouse cone photoreceptor cells. In-

Cowan CW, Fariss RN, Sokal I, Palczewski K, Wensel TG (1998) High expression levels in cones of RGS9, the predominant GTPase accelerating protein of rods. Proc Natl Acad Sci USA 95:5351-5356.

Daniele LL, Lillo C, Lyubarsky AL, Nikonov SS, Philp N, Mears AJ, Swaroop A, Williams DS, Pugh Jr EN (2005) Cone-like morphological, molecular, and electrophysiological features of the photoreceptors of the $\mathrm{Nrl}$ knockout mouse. Invest Ophthalmol Vis Sci 46:2156-2167.

Davis TL, Bonacci TM, Sprang SR, Smrcka AV (2005) Structural and molecular characterization of a preferred protein interaction surface on $G$ protein betagamma subunits. Biochemistry 44:10593-10604.

Elias RV, Sezate SS, Cao W, McGinnis JF (2004) Temporal kinetics of the light/dark translocation and compartmentation of arrestin and alphatransducin in mouse photoreceptor cells. Mol Vis 10:672-681.

Feig LA (2006) The odyssey of k-ras. Mol Cell 21:447-449.

Fung BK, Hurley JB, Stryer L (1981) Flow of information in the lighttriggered cyclic nucleotide cascade of vision. Proc Natl Acad Sci USA 78:152-156.

Fung BK, Lieberman BS, Lee RH (1992) A third form of the G protein beta vest Ophthalmol Vis Sci 46:12-16. 
subunit. 2. Purification and biochemical properties. J Biol Chem 267:24782-24788.

Garwin GG, Saari JC (2000) High-performance liquid chromatography analysis of visual cycle retinoids. Methods Enzymol 316:313-324.

Gilman AG (1987) G proteins: transducers of receptor-generated signals. Annu Rev Biochem 56:615-649.

He W, Cowan CW, Wensel TG (1998) RGS9, a GTPase accelerator for phototransduction. Neuron 20:95-102.

Kassai H, Aiba A, Nakao K, Nakamura K, Katsuki M, Xiong WH, Yau KW, Imai H, Shichida Y, Satomi Y, Takao T, Okano T, Fukada Y (2005) Farnesylation of retinal transducin underlies its translocation during light adaptation. Neuron 47:529-539.

Kennedy MJ, Lee KA, Niemi GA, Craven KB, Garwin GG, Saari JC, Hurley JB (2001) Multiple phosphorylation of rhodopsin and the in vivo chemistry underlying rod photoreceptor dark adaptation. Neuron 31:87-101.

Kennedy MJ, Dunn FA, Hurley JB (2004) Visual pigment phosphorylation but not transducin translocation can contribute to light adaptation in zebrafish cones. Neuron 41:915-928.

Kerov V, Chen D, Moussaif M, Chen YJ, Chen CK, Artemyev NO (2005a) Transducin activation state controls its light-dependent translocation in rod photoreceptors. J Biol Chem 280:41069-41076

Kerov VS, Natochin M, Artemyev NO (2005b) Interaction of transducinalpha with LGN, a G-protein modulator expressed in photoreceptor cells. Mol Cell Neurosci 28:485-495.

Kokame K, Fukada Y, Yoshizawa T, Takao T, Shimonishi Y (1992) Lipid modification at the $\mathrm{N}$ terminus of photoreceptor G-protein alphasubunit. Nature 359:749-752.

Kuhn H (1980) Light- and GTP-regulated interaction of GTPase and other proteins with bovine photoreceptor membranes. Nature 283:587-589.

Lee KA, Craven KB, Niemi GA, Hurley JB (2002) Mass spectrometric analysis of the kinetics of in vivo rhodopsin phosphorylation. Protein Sci 11:862-874.

Lee SJ, Montell C (2004) Light-dependent translocation of visual arrestin regulated by the NINAC myosin III. Neuron 43:95-103.

Lee SJ, Xu H, Kang LW, Amzel LM, Montell C (2003) Light adaptation through phosphoinositide-regulated translocation of Drosophila visual arrestin. Neuron 39:121-132.

Levitzki A, Klein S (2002) G-protein subunit dissociation is not an integral part of G-protein action. Chembiochem 3:815-818.

Lobanova ES, Finkelstein Song, Tsang Chen, Sokolov Skiba, Arshavsky (2007) Transducin translocation in rods is triggered by saturation of the GTPase-activating complex. J Neurosci 27:1151-1160.

Marszalek JR, Liu X, Roberts EA, Chui D, Marth JD, Williams DS, Goldstein LS (2000) Genetic evidence for selective transport of opsin and arrestin by kinesin-II in mammalian photoreceptors. Cell 102:175-187.

McConnachie G, Langeberg LK, Scott JD (2006) AKAP signaling complexes: getting to the heart of the matter. Trends Mol Med 12:317-323.

Mears AJ, Kondo M, Swain PK, Takada Y, Bush RA, Saunders TL, Sieving PA, Swaroop A (2001) Nrl is required for rod photoreceptor development. Nat Genet 29:447-452.

Mendez A, Lem J, Simon M, Chen J (2003) Light-dependent translocation of arrestin in the absence of rhodopsin phosphorylation and transducin signaling. J Neurosci 23:3124-3129.

Nair KS, Hanson SM, Kennedy MJ, Hurley JB, Gurevich VV, Slepak VZ (2004) Direct binding of visual arrestin to microtubules determines the differential subcellular localization of its splice variants in rod photoreceptors. J Biol Chem 279:41240-41248.

Nair KS, Hanson SM, Mendez A, Gurevich EV, Shestopalov VI, Vishnivetskiy
SA, Kennedy MJ, Chen J, Hurley JB, Gurevich VV, Slepak VZ (2005a) Light-dependent re-distribution of arrestin in vertebrate rods is an energy-independent process governed by protein-protein interactions. Neuron 46:555-567.

Nair KS, Mendez A, Blumer JB, Rozenzveig D, Slepak VZ (2005b) The presence of Leu-Gly-Asn repeat enriched protein, LGN, a putative binding partner for transducin, in photoreceptors. Invest Ophthalmol Vis Sci 46:383-389.

Neubert TA, Johnson RS, Hurley JB, Walsh KA (1992) The rod transducin alpha subunit amino terminus is heterogeneously fatty acylated. J Biol Chem 267:18274-18277.

Northup JK, Smigel MD, Sternweis PC, Gilman AG (1983) The subunits of the stimulatory regulatory component of adenylate cyclase. Resolution of the activated 45,000-dalton (alpha) subunit. J Biol Chem 258:11369-11376.

Ong OC, Yamane HK, Phan KB, Fong HK, Bok D, Lee RH, Fung BK (1995) Molecular cloning and characterization of the $G$ protein gamma subunit of cone photoreceptors. J Biol Chem 270:8495-8500.

Otto-Bruc AE, Fariss RN, Van Hooser JP, Palczewski K (1998) Phosphorylation of photolyzed rhodopsin is calcium-insensitive in retina permeabilized by alpha-toxin. Proc Natl Acad Sci USA 95:15014-15019.

Palczewski K, McDowell JH, Hargrave PA (1988) Purification and characterization of rhodopsin kinase. J Biol Chem 263:14067-14073.

Peet JA, Bragin A, Calvert PD, Nikonov SS, Mani S, Zhao X, Besharse JC, Pierce EA, Knox BE, Pugh Jr EN (2004) Quantification of the cytoplasmic spaces of living cells with EGFP reveals arrestin-EGFP to be in disequilibrium in dark adapted rod photoreceptors. J Cell Sci 117:30493059.

Peterson JJ, Orisme W, Fellows J, McDowell JH, Shelamer CL, Dugger DR, Smith WC (2005) A role for cytoskeletal elements in the light-driven translocation of proteins in rod photoreceptors. Invest Ophthalmol Vis Sci 46:3988-3998.

Saari JC, Nawrot M, Garwin GG, Kennedy MJ, Hurley JB, Ghyselinck NB, Chambon P (2002) Analysis of the visual cycle in cellular retinolbinding protein type I (CRBPI) knockout mice. Invest Ophthalmol Vis Sci 43:1730-1735.

Smrcka AV, Scott JK (2002) Discovery of ligands for beta gamma subunits from phage-displayed peptide libraries. Methods Enzymol 344:557-576.

Sokolov M, Lyubarsky AL, Strissel KJ, Savchenko AB, Govardovskii VI, Pugh Jr EN, Arshavsky VY (2002) Massive light-driven translocation of transducin between the two major compartments of rod cells: a novel mechanism of light adaptation. Neuron 34:95-106.

Sokolov M, Strissel KJ, Leskov IB, Michaud NA, Govardovskii VI, Arshavsky VY (2004) Phosducin facilitates light-driven transducin translocation in rod photoreceptors. Evidence from the phosducin knockout mouse. J Biol Chem 279:19149-19156.

Strissel KJ, Lishko PV, Trieu LH, Kennedy MJ, Hurley JB, Arshavsky VY (2005) Recoverin undergoes light-dependent intracellular translocation in rod photoreceptors. J Biol Chem 280:29250-29255.

Strissel KJ, Sokolov M, Trieu LH, Arshavsky VY (2006) Arrestin translocation is induced at a critical threshold of visual signaling and is superstoichiometric to bleached rhodopsin. J Neurosci 26:1146-1153.

Wang Y, Windh RT, Chen CA, Manning DR (1999) N-Myristoylation and betagamma play roles beyond anchorage in the palmitoylation of the $\mathrm{G}$ protein alpha(o) subunit. J Biol Chem 274:37435-37442.

Wolfrum U, Giessl A, Pulvermuller A (2002) Centrins, a novel group of $\mathrm{Ca}^{2+}$-binding proteins in vertebrate photoreceptor cells. Adv Exp Med Biol 514:155-178. 